\title{
10 Learning from Performance Improvement: The New Zealand Experience and Insights on How a Performance System Survives
}

\author{
Barbara Allen 0000-0001-5662-5649
}

\section{Introduction}

We are inching forward in our knowledge about performance management and performance improvement. Millions of words have been written about performance in the public sector, and we continue to churn out studies and results of surveys, cases, and experiments. It is undeniable that there is something very important about whether the public sector 'works' and how it 'performs', as well as how 'productive' it is - how taxpayer money is spent and whether citizens' lives are improved through public sector spending is one of the most important problems of public administration.

The problem of performance has been addressed at the macro, meso, and micro levels; this makes sense because it is impossible to consider 'public sector performance' all in one undertaking. Policy analysis, programme evaluation, and individual- and group-level performance monitoring have been the subject of a significant number of studies, but at the level of organizational capacity there has been much less focus. We have been particularly interested in performance frameworks put in place by central agencies to monitor organizational performance. At this level, we see how organizational strategy intersects with operational capacity or lack thereof.

This chapter draws on previous and ongoing research undertaken by academics at the School of Government, Te Herenga Waka Victoria University Wellington, New Zealand. In 2017, a team from the school was commissioned by the State Services Commission (SSC) to review the New 
Zealand Performance Improvement Framework (PIF). The review led to a conference paper, a journal article, a book chapter (forthcoming) comparing the PIF to the Canadian Management Accountability Framework (MAF), and numerous speaking engagements, and we continue to pursue further research on the topic. There has been considerable interest in the PIF and New Zealand's approach. Here we look broadly at what we have learned, reflecting on the PIF as an organizational performance system and how it compares to other systems, notably the MAF. The second part of the chapter is reflective, outlining key insights on performance using the lens of organizational-level frameworks in different settings.

\section{The New Zealand Performance Improvement Framework (PIF)}

Any government performance system that survives intact for more than ten years has to be considered a success. Given the complexities of how public administration intersects with politics, it is not surprising that public sector evaluation and review systems come and go as often as leadership changes occur. It is relatively rare to see a system that monitors organizational performance remain largely recognizable many years later.

The PIF in New Zealand is an example of an organizational framework that has evolved and changed; it has survived political change, significant structural adjustment, and ongoing questions about its usefulness. We look to our evaluation of the New Zealand PIF for learning as well as our comparison to the Canadian MAF.

\section{The PIF and Performance through 'Better Public Services' - A Brief}

\section{Overview}


The PIF emerged in 2009 and was initially based on the United Kingdom's Capability Reviews (Te Kawa and Guerin, 2012) but with carefully thought-through adaptations for the New Zealand environment. It has been upgraded and changed at least four times. It has had various iterations and has been described in different but related ways:

- A uniform, yet flexible, framework to support continuous performance improvement across the State Services (SSC, 2015)

- A joint central agency initiative to help senior leaders improve the performance of the agencies they lead (SSC, n.d.).

The PIF emerged from a period in which New Zealand was implementing what came to be known as New Public Management; New Zealand was pushing harder and farther than any other country. The objectives of this reform were described as an effort to

- improve allocative and productive efficiency;

- enhance the effectiveness of governmental programmes;

- improve the accountability of public sector institutions and the accountability of the executive to Parliament;

- reduce the level of government expenditure and the size of the core public sector;

- minimize the quality of the goods and services produced by the public agencies; and

- make public services more accessible and responsive to consumers (Boston, 1996).

The PIF became part of the New Zealand performance regime, a regime is described as the as the 'interactions among a multitude of institutions and instruments ... which can play a role in regulating the performance of public service organizations, operating within systems of formal 
and informal rules and cultures' (Talbot et al., 2005; Talbot 2010) as cited in Martin et al. (2016)(131).

- In the New Zealand context, 'Perhaps the most significant development in the public services since 1999 has been the shift away from an almost exclusive concern with the efficient production of outputs to an emphasis on the achievement of positive outcomes for citizens' (Shaw, 2006, p.281). In New Zealand, and elsewhere, this transition is related to a shift from NPM to what is called Public Value, Public Value Management, or even New Public Governance. This was a move from primacy of efficiency criterion (ex-ante) to achieving public value (ex-post);

- from centralization of policy control to dispersed policy control;

- from separation to reintegration of function (policy/delivery/oversight) and roles (purchaser/provider);'

- from preferences for marketization, contestability, and non-state sector delivery to a more context-specific approach that draws on public, private, and/or voluntary sector;

- from rigid to more nuanced and diffuse accountability arrangements that shift the focus from managers and political principals to ministers with multiple and direct accountabilities to, and among, citizens; and

- from the focus on customer/consumer needs to a focus on citizen engagement and fulfilment. It still remains to be seen whether public value and its iterations are an accurate description of change actually occurring in the state. There is a growing literature around this, with time having passed for academics to consider whether it is indeed a 'shift' or a 'layering' or some sort of hybrid (Goldfinch and Yamamoto, 2019; Macaulay, 2020). An expanding literature on public value does not necessarily mean that change as envisioned is occurring, as ongoing debates Barbara Allen 
around the nature of change of public systems - to what extent public administration has moved from bureaucracies, to markets, to networks, and back again - may allude to the fact that the problems we hoped public value would solve have not yet been solved. The PIF has remained a part of this landscape, and its evolution is one example of the attempt to alter thinking towards a focus on 'outcomes for citizens'. The addition of the 'Four-year Excellence Horizon', which was introduced in 2011, and then further change in 2015 to focus on customers and the 'delivery of value to New Zealanders' may be reaping rewards in terms of organizational strategic thinking, but there is little evidence to actually demonstrate this change.

The PIF itself involves a number of stages starting with a self-review of the organization; a negotiation with the overseeing central agency with respect to the timing and choice of (external) reviewers; the in-organization review typically lasting two to three weeks where reviewers interview members at all levels, including stakeholders outside the organization; a detailed report by the reviewers; and a final arrangement on the negotiated report that will be published on the (public) Internet site.

The most recent published report serves as a good example. The Review of Te Puni Kokiri (Ministry of Māori Development; SSC, 2020) begins with a section on commitment 'Accepting the Challenge'; 'The Challenge' that sets out the Four-year Excellence Horizon is underpinned by the key question: 'What is the agency's performance improvement challenge?' This is broken down into 'Delivering Government Priorities - How well is the agency responding to government priorities?' - 'Delivering Core Business':

- In each core business area, how well does the agency deliver value to its customers and New Zealanders?

- In each core business area, how well does the agency demonstrate increased value over time? 
- How well does the agency exercise its stewardship role over regulation?

The section on Organizational Management asks 'How well is the agency positioned to deliver now and in the future?' based on five key areas: Leadership and Direction, Delivery for Customers and New Zealanders, Relationships, People Development, and Financial and Resource Management.

The ratings are an interesting mix of 'scoring' and 'behavior incentivization', broken down by Value to customers and New Zealanders and Increased value over time. The ratings are by colour and descriptor: 'Strong', 'Well-placed', 'Needing development', 'Weak', and 'Not able to rate'. The PIF process depends on the 'Lead Reviewer' approach. Lead reviewers are usually highly experienced ex-public sector officials with significant leadership experience and deep knowledge of the New Zealand public sector. The two reviewers assigned to an organization's PIF set the tone for the exercise and to a large extent determine the balance between whether the exercise becomes one of 'assess' or 'assist' (Allen and Eppel, 2020.

Ultimately, the report is a mixture of narrative and narrative-around-ratings. In our article published in the Australian Journal of Public Administration (Allen and Eppel, 2020), we grappled with the extent to which the PIF is a compliance exercise or an improvement exercise or something else altogether (the assess or assist). It does appear that the Public Services Commission (this name changed in 2020) has worked hard at reducing the negative impacts of the ratings approach while not losing the positive ones - ratings and scoring tend to attract attention and become 'the' element that people remember. Seeing the part for the whole, or conversely the whole for the part, is highly problematic in these circumstances. Also known as synecdoche, there is always the danger that particularly bad (or good) ratings in one section 
become the story of the entire report, or a good 'story' could be taken as the entire result where actually in the details lies a much more challenging situation for the organization.

Along with the PIF, for a few years the New Zealand performance regime involved the Better Public Services Programme (BPSP), established in 2013 but cancelled when the new government took over in 2017. While the PIF, at the time, seemed to be inward-facing, the BPSP was aimed at levering programme outcomes, perhaps in a more traditional fashion with targets linked to government policy. Under this initiative, ministers chose ten cross-cutting problems and set up a five-year target in each area. Each of the ten targets fell into five policy areas and followed the public sector outcomes corresponding to: (1) reducing welfare dependence, (2) supporting valuable children, (3) boosting skills and employment, (4) reducing crime, and (5) improving interaction with government. In contrast with the PIF, the BPSP was related to impacts, to measurable effects, whereas the PIF reviews, at least early on, were related to internal criteria, to norms and values about good public administration. Or, as described in official materials:

'Where PIF is all about jobs we do, and improving the workplaces for public servants so they can do their jobs better, BPSP is also about improving what we do on behalf of, and for, New Zealanders.'(SSC, 2014)

However, with the demise of BPSP, the very specific wide-ranging set of targets was dropped, but the PIF continued.

\section{Comparisons and What We Learned from Comparing the PIF to the MAF}

In our original evaluation of the PIF, we undertook a brief comparison of the United Kingdom's Capability Reviews (2005-2012); the United Kingdom's Departmental Improvement Plans (2013-); Australia’s Capability Reviews (2011-2015); Australia’s Capability Maturity Model 
(2011-); South Africa's Management Performance Tool (2011-); Norway's Management-byObjectives-and-Results (1986-); and Canada’s Management Accountability Framework (2003-) (Allen et al., 2017). We found that there were similarities across the systems, but we had good reason to later focus on the MAF in comparable sense as both emerged from pressures in the 1990s and 2000s to encourage senior leadership to look more closely at their high-level departmental challenges as well as to dig into their strategic direction, values and ethics, risk management, accountability, and change management. The MAF was like the PIF in that it was a top-down initiative from a central agency looking to develop full assessments of organizational performance to inform decision-makers and to look at organizational capacity as opposed to individual sub-unit level (Allen et al., 2019). We discovered that the Canadian approach was directed more at understanding organizational performance from the past and the PIF, overall, was a more flexible and future-focused system.

The MAF in its motivations was aimed at providing a comprehensive assessment and overview of organizational performance, largely in administrative policy domains, that was unrelated to policies or programmes, as well as to inform deputy ministers and agency heads in their discussions with executive teams. In its origins, it was built upon the Modern Comptrollership Initiative of the mid-to-late 1990s that was aimed at giving better financial and nonfinancial information.

The MAF evolved through different iterations of the broad categories of indicators; namely governance and strategic direction, values and ethics, risk management, accountability, and change management. The MAF has its own online portal to which departments submit their information; the Treasury Board Secretariat assesses submissions, gets feedback from departments and agencies, and final reports are set for use by deputy ministers and the Privy 
Council Office. The MAF reports are involved in the Privy Council Office reviews of deputy ministers' performance. High-level comparisons do emerge publicly, but detailed comparisons remain internal documents. What has emerged through evaluation includes issues with resource intensity, the changing indicators and lines of evidence, and a lack of independent data as opposed to self-reporting that might provide more genuine information. It seems that department and agency heads view the MAF with some concern in terms of a lack of strategic focus and value that can emerge from having a lens on the long-term role of the organizations (Lindquist, 2016b, 2017).

As we noted in our initial paper, the essentially backward-looking MAF and the forward-looking PIF raise important questions. We do not really know the relative merits of backward-looking methodologies that rely on multiple indicators and provide essentially an assessment in the form of a comprehensive 'systems check, but nor do we fully know the merits of a more forwardlooking methodology for a review, possibly less rooted in the systematic collection of data, but in contrast reflecting the views of lead and peer reviewers rather than detailed lines of data and information" (Allen et al., 2017).

The New Zealand approach has gradually reduced the emphasis on functional reporting - there are many other tools in the system and the Public Services Commission has worked at integrating strategic thinking with operational capacity and development. The PIF has been particularly successful at building on an interviewing approach, interviews undertaken by the lead reviewers and combined with both the self-review and observations by the reviewers. In previous work, we concluded that gaming behaviour persists and the ratings still hold an inordinate emphasis with a danger that the ratings will result in becoming a proxy for the performance of the whole organization. We also suggested that the PIF contributes to and 
influences reputation-protecting behaviour. There is no doubt that any publicly reported performance report of a public sector organization will be a factor in reputation. New Zealand is small, most chief executives know one another, and there is an implicit system of influenceenhancing activity. However, this is no different than any other comparable country. Risk management and compliance exercises are part of the accountability and performance regime - it is a matter of scale and will always have their place.

We placed the PIF and the MAF on a scale mapping the ecosystem of central agency needs and public service organization needs and function focus versus strategy focus. The MAF landed closer to the 'function focus' and towards central agency needs rather than the organizational needs. The PIF lands high on both central agency needs and strategy focus. Without further research it is not entirely clear whether the PIF meets the needs of the all stakeholders involved; our 2017 evaluation suggested that the PIF has many positive attributes:

- Generally speaking, public servants perceive the PIF review as high quality and highly accurate.

- Lead reviewers are seen as credible and upholding public service standards.

- Public servants perceive that since their PIF review their organization ensures its contribution to New Zealand is better.

- It is generally perceived as having long-term strategic value.

The tensions are not unique, perhaps; the long-term implementation and strategic focus of a government department comes up against political expediency in every system. The MAF has struggled to move beyond its information-based review into a more strategic tool. This leaves us with some key insights. 


\section{Insight 1 - The PIF Is Working - Maybe}

Do PIFs at the organizational level work? Despite the vast literature on performance management, we still do not have a lot of empirical data to work with at this level, and, my sense is that we still do not know. The New Zealand government has been confident enough in its PIF to maintain and continue using this approach, and the Public Services Commissioner (until recently the State Services Commissioner) has seen enough value in continuing it. New Zealand now has 84 PIF reviews (including follow-up and shorter specific issue reviews) publicly available, which demonstrates at minimum an interest in maintaining this organizational-level assessment of its public sector and in its best light a fairly comprehensive system of performance evaluation that is accomplishing the objectives set out and perhaps some that are much more internal and even unspoken: this may be a kind of control that it achieves no other way. The PIF system has survived three elections, major changes in the public services through reform, and plenty of criticism. Our evaluations did find many positive things though rigorous research needs to be done to see how organizations change over time 'due to the PIF', as opposed to any other performance trigger. By studying the organizations that have had multiple reviews and follow-up reviews it may be possible to understand what changes have emerged, although it would still be difficult to ascertain if the changes are even partially due to their PIF process.

\section{Insight 2 - Comparing the PIF Will Be a Useful Way Forward}

Comparative public administration research has been a growing field, and there are a number of books and articles that attempt to classify, segment, contrast, and evaluate different performance approaches and regimes (Bouckaert and Halligan, 2008; Jakobsen et al., 2018). There is still not 
much literature on organizational performance improvement of the type we undertook in our analyses. We found our comparison to be enormously instructive such that we were able to suggest changes to both systems.

The problem of course is dealing with the problem of 'equivalence'. Effective comparison requires finding a useful comparator, and we are fortunate that two systems, the New Zealand PIF and the Canadian MAF, provide a good level of variables for comparison. However, taking into account the many elements that are very different, we can see the scale, scope, and the nature of the government systems (federal vs. unitary) leads to a whole host of comparative issues.

\section{Insight 3 - Adaptability and Evaluation}

The PIF has survived because of its adaptability. Officials in central agencies have to be willing to persist with the organizational performance frameworks and be willing and able to convince their political leaders that there is reason and benefit to continue. Including these organizational reviews in the performance reviews of the chief executives or deputy minister of key departments begins to link up different levels of performance review and improvement. A process of continuous evaluation needs to be integrated into the setup from the outset - this definitely seems to be missing from organizational improvement frameworks. While ad hoc reviews and internal reviews are helpful, a full theory of change applied to the implementation with a scheduled external review would establish the evidence base needed to understand what is working and what is not and which types of organizations require more regular PIFs and which do not. 


\section{Insight 4 - The Links between Performance Systems Are Weak and Need to Be}

\section{Analysed Empirically in More Contexts}

A few authors have partially undertaken this challenge - in their study on high performance public service organizations for the Australian Public Service Commission, Blackman et al. (2012) produced an analytic framework outlining different levels of analysis - government-wide, organizational, and group and individuals - which performance systems might work at. Here we note that the government level can include government policies, and that both policies and programmes alike might be monitored at the organization level, which is different from measuring the health and performance of particular departments and agencies. A second perspective comes from Talbot (2010) Theories of Performance, a book consolidating many of his insights, including the concept of 'performance regimes' and emphasizing the institutional context and variety of performance interventions, a critique of essentially 'organizational models of performance'.

However, there is little empirical work that maps the national performance improvement systems at the organizational level. The SSC of New Zealand was referring to their own system in the 2013 summary of the PIF reviews to that point, but no doubt it holds true in many others:

'Agencies are better at managing issues and keeping their Ministers happy than they are at building core institutional capability that adds substantial and enduring value....'

We end this chapter on that note - core institutional capability that provides a solid foundation for dealing with anything that emerges, be it political change, disasters, or health emergencies, is a critical element of a nation's strength that cannot be ignored or assumed away. Focus on performance improvement through tried and tested experiences as part of a regime of 
Barbara Allen

accountability, operational excellence, and institutional resilience is more important than ever for researchers to study and provide advice on to their public sector systems.

\section{References}

Allen, B., Berman, E., Cantal, C., Eppel, E., Jackson, B., Löfgren, K., Macaulay, M., Plimmer, G., and Phillips, B. (2017). Independent Review of the Performance Improvement Framework (i-45 Report). Wellington: Victoria University, School of Government of Government.

Allen, B., and Eppel, E. (2020) 'Holding on Tight - NPM and the New Zealand performance improvement framework', Australian Journal of Public Administration 79(2), 171-186.

Allen, B., Lindquist, E., and Eppel, E. (2019). From Measuring Government Performance to Assessing Organizational Capacity: Lessons from Canada and New Zealand. Conference paper at the International Research Symposium for Public Management, 14 April, Victoria University, Wellington, New Zealand.

Allen, B., and Linquist, E. (Forthcoming). Assessing Organization Performance in Public Sector Systems: Lessons from Canada's MAF and New Zealand's PIF. In D. Blackman, F. Buick, K. Gardner, S. Johnson, M. O’Donnell, and S.E. Olney (Eds.), Handbook on Performance Management in the Public Sector.

Blackman, D., Buick, F., O’Donnell, M., O’Flynn, J., and West, D. (2012). Developing High Performance: Performance Management in the Australian Public Service, Crawford School Working Paper No. 12-09, Crawford School of Public Policy, Australian National University, Canberra.

Boston, J. (Ed.) (1996). Public Management: The New Zealand Model. Auckland and New York: Oxford University Press, 4. 
Barbara Allen

Bouckaert, G., and Halligan, J. (2008). Managing Performance: International Comparisons. Abingdon: Routledge.

Goldfinch, S., and Yamamoto, K. (2019). Citizen Perceptions of Public Management:

Hybridisation and Post-new Public Management in Japan and New Zealand. Australian Journal of Public Administration, 78(1), 79-94.

Jakobsen, M., Baekgaard, M., Moynihan, D., and van Loon, N. (2018). Making Sense of Performance Regimes: Rebalancing External Accountability and Internal Learning. Perspectives on Public Management and Governance, 1(2), 1-15.

Lindquist, E.A. (2009). How Ottawa Assesses Department/Agency Performance: Treasury Board's Management Accountability Framework. Chapter 3 in Allan M. Maslove (Ed.), How Ottawa Spends 2009-2010: Economic Upheaval and Political Dysfunction. McGill-Queen's University Press, pp. 47-88.

Lindquist, E.A. (2016a). Deliverology: Lessons and Prospects. Canadian Government Executive (March 17). https://canadiangovernmentexecutive.ca/deliverology-lessons-and-prospects/ Lindquist, E.A. (2016b). Performance Monitoring and the Management Accountability Framework: Recent Developments, Perspective, and Insights from the Literature, prepared for the Treasury Board of Canada Secretariat, October 2016.

Lindquist, E.A. (2017). Rethinking the Management Accountability Framework and Performance Monitoring for the Digital Era. Chapter 11 in K.A.H. Graham and A.M. Maslove (Eds.), How Ottawa Spends 2017-2018: Canada @ 150. Carleton University, School of Public Policy and Administration, pp. 132-142. https://carleton.ca/hos/wpcontent/uploads/How-Ottawa-Spends-2017-2018-Ottawa-@150.pdf 
Macaulay, M. (2020). In Search of a Golden Thread: Recent Developments in Public Management Across New Zealand and Australia. Public Management Review. DOI: 10.1080/14719037.2020.1796289.

Martin, S., Nutley, S., Downe, J., and Grace, C. (2016). Analysing Performance Assessment in Public Services: How useful is the Concept of a Performance Regime? Public Administration, 94(1), 129-145.

Shaw, R. (2006) “The Public Service," in New Zealand Government and Politics, ed. Raymond Miller, 5th ed. Melbourne: Oxford University Press.

State Services Commission, Government of New Zealand (2014). Annual Report for Year Ended 30 June 2014. State Services Commission Annual Report for the Year Ended 30 June 2014. https://www.publicservice.govt.nz/resources/|

State Services Commission, Government of New Zealand (2015). www.ssc.govt.nz/resources/pif-framework/

State Services Commission, Government of New Zealand (n.d.). http://ssc.govt.nz/performanceimprovement-framework

State Services Commission, Government of New Zealand (2020). Performance Improvement Framework. Review for Te Puni Kokari (Ministry of Maori Development). https://www.publicservice.govt.nz/assets/SSC-Site-Assets/System-and-AgencyPerformance/PIF-Report-TPK-August-2020.pdf 
Barbara Allen

Talbot, C., Johnson, C., and Wiggan, J. (2005). Exploring Performance Regimes - A Report for the National Audit Office. Manchester Business School: Centre for Public Policy and Management.

Talbot, C. (2010). Theories of Performance: Organisational and Service Improvement in the Public Domain. Oxford: Oxford University Press.

Te Kawa, D., and Guerin, K. (2012). Provoking Debate and Learning Lessons. Policy Quarterly, Vol. 8, No. 4. DOI: https://doi.org/10.26686/pq.v8i4.4430 